\title{
O devir-consciente em rodas de poesia ${ }^{\star}$
}

\author{
Virgínia Kastrup ${ }^{\star \star}$
}

\section{RESUMo}

O texto discute o conceito de devir-consciente, proposto por Depraz, Varela e Vermersch (2003), à luz de uma experiência de rodas de poesia no contexto de um trabalho comunitário com mulheres de classes populares. Apresenta o ciclo básico e a intuição que caracterizam o devir-consciente, sugerindo que esta é uma prática de produção de subjetividade. Analisa o caso específico do devir-consciente de experiências de breakdown (VARELA, 1994), que acessam o plano pré-subjetivo da cognição e que se potencializam na situação grupal através de uma dinâmica de ressonâncias. A roda de poesia revela uma dimensão coletiva da cognição e é proposta uma modalidade de relato que busca dar expressão a ela. A partir desta experiência de cognição coletiva, são levantadas questões relativas aos métodos de primeira e segunda pessoas que se apresentam no campo das ciências cognitivas contemporâneas.

Palavras-chave: Devir-consciente. Cognição coletiva. Metodologias de primeira pessoa. Roda de poesia.

\section{On becoming aware in poetry reading}

\begin{abstract}
In this work we discuss the concept of "becoming-aware", as defined by Depraz, Varela, and Vermersch (2003), in the light of an experience of poetry reading in the context of a community work with lower class women. We present the basic cycle and the intuition that characterize the becoming-aware,

^ $\mathrm{O}$ artigo constitui uma versão reformulada da palestra apresentada por ocasião da Jornada Internacional de Pesquisa "O devir-consciente e a pragmática da experiência": em torno de On becoming aware, de Natalie Depraz, Francisco Varela e Pierre Vermersch, que ocorreu de 19 a 26 de abril de 2004 no Instituto de Psicologia da UFRJ e no Departamento de Psicologia da UFF. Foi organizado pelo Programa de Pós-Graduação em Psicologia da Universidade Federal do Rio de Janeiro, pelo Mestrado em Psicologia da Universidade Federal Fluminense e pelo Departamento de Filosofia da Universidade Paris IV, em abril de 2003. A pesquisa que deu origem ao artigo foi apoiada pelo CNPq. Os alunos participantes foram Paula Rego Monteiro, Carla Neves, Paula Cordeiro, Helen de Abreu Oliveira, Tamara Nascimento e Rodrigo Nascimento, aos quais agradecemos a colaboração e implicação em todas as etapas do trabalho.

$\star \star$ Professora do Programa de Pós-Graduação em Psicologia da Universidade Federal do Rio de Janeiro - UFRJ. Endereço: Rua Professor Ortiz Monteiro 276, ap. 401, B1.A. Laranjeiras, Rio de Janeiro, RJ. Cep: 22245-100.

E-mail: vkastrup@ terra.com.br
\end{abstract}


suggesting that this is a practice of production of subjectivity. We also analyze a particular case of becoming-aware in experiences of breakdown (VARELA, 1994), which mobilize the pre-subjective level of cognition and empower group situation by means of a dynamics of resonances. Since the practice of poetry reading reveals a collective dimension of cognition, we propose a modality of writing which would be adequate to express it. Based on this experience of collective cognition, we bring up issues concerning the methods of first and second persons in the field of contemporary cognitive sciences.

Keywords: Becoming aware. Collective Cognition. First-person methodology. Poetry reading.

\section{O DEVIR-CONSCIENTE E A CRIAÇÃo DE UM MÉTODO PARA SUA INVESTIGAÇÃo}

No início da segunda metade do século XX, o surgimento das ciências cognitivas fez com que o estudo da mente retornasse ao cenário científico, mas só nos últimos anos assiste-se à retomada da investigação da consciência. Pela quantidade de artigos e livros dedicados a esse tema, a década de 1990 é considerada a década da consciência. Até esta data foi dominante na área uma concepção da cognição como processamento de informações, que deixa de fora sua dimensão experiencial. O exemplo mais notável é o cognitivismo computacional, que restringe a atividade mental ao processamento de símbolos por regras lógicas. Entre o estudo da mente e a retomada da consciência passou-se quase meio século. Esta retomada significa uma reconciliação entre as ciências cognitivas e a experiência (VARELA; THOMPSON; ROSCH, 2003). No campo da psicologia científica, o tema da experiência já havia sido expurgado em função do veto positivista, proferido por Augusto Comte (1842/1972) no seu Curso de Filosofia Positiva. Para Comte, ou bem fazemos ciência ou bem estudamos a experiência, pois o estudo da realidade subjetiva é necessariamente carregado de subjetivismo. As críticas de Comte ao método da introspecção tornaram-se célebres e produziram forte efeito sobre o campo da psicologia, que pode ser evidenciado pela força assumida pelo behaviorismo durante quase quatro décadas. Pode-se concluir então que, num primeiro momento, as ciências cognitivas rompem com o behaviorismo no sentido em que propõem uma nova ciência da mente. No entanto, aproximam-se dele, pois ambos deixam de fora da investigação científica o tema da consciência. Nos dias atuais, a elaboração de uma ciência da consciência é um difícil, mas urgente desafio.

Uma das tentativas de resenhar algumas das posições recentes mais significativas nessa área foi empreendida por John Searle (1998) em seu livro O mistério da consciência. Searle afirma que a questão da atualidade é transformar esse mistério num problema passível de investigação rigorosa por parte de filósofos e cientistas. As abordagens da consciência apresentadas no livro de Searle formam um espectro variado de posições, muitas delas conflitantes. As teorias de Francis Crick, Gerald Edelman, Roger Penrose, Daniel Dennett, David Chalmers e Israel 
Rosenfield são comentadas numa ampla discussão, na qual ganham destaque o problema mente-corpo, as recentes polêmicas acerca da distinção entre o dualismo de substância e de propriedades, o papel do sistema nervoso na emergência da consciência e as possibilidades e limites dos modelos computacionais. Todavia, cabe ressaltar que os autores dos textos reunidos nesta coletânea colocam ênfase nas questões teórico-conceituais, não apresentando propostas efetivas para subsidiar estratégias de investigação de experiências concretas que têm lugar na consciência.

Diante deste cenário, ganha destaque a contribuição de Francisco Varela que, embora ausente do livro de Searle, possui um dos trabalhos mais inovadores na contemporaneidade. Em primeiro lugar, a originalidade de sua abordagem reside em estudar a consciência tendo rompido com o modelo da representação, o que se evidencia na teoria da autopoiese, formulada em parceria com Humberto Maturana (MATURANA; VARELA, 1995), e também na abordagem da enação (VARELA, 1994). Nos anos 1990, Varela desenvolveu dois eixos de pesquisa distintos e complementares. O primeiro situa-se na área das neurociências e voltase para o estudo do cérebro, através das recentes tecnologias de pesquisa. Cabe sublinhar que as técnicas de ressonância magnética produziram um grande avanço nessa área, por sua notável superioridade em relação ao antigo registro através do eletro-encefalograma, pois permitiram a observação do funcionamento do cérebro frente a situações momentâneas específicas. A pesquisa de Varela e sua equipe buscou investigar a dinâmica da atividade cerebral em certos momentos da experiência. Resultou daí a teoria da sincronização em larga escala, apresentada no artigo "The brainweb: phase synchronization and large-scale integration" (VARELA et al., 2001). Segundo esta teoria, os neurônios possuem uma oscilação constante. Num certo momento diversos pontos do cérebro passam a oscilar juntos, entrando em sincronia. O mecanismo revela a formação transitória de grupos síncronos, envolvendo não apenas neurônios em contigüidade espacial, mas também distantes e distribuídos de maneira ampla pelo cérebro. A sincronia surge e desaparece em seguida, revelando uma dinâmica cerebral semelhante a ondas que emergem e se desfazem, sem que tal funcionamento tenha um centro de controle. Em termos metodológicos, a magnetoscopia situa-se no âmbito dos chamados métodos de terceira pessoa. Ela lança mão da observação externa, mantendo distintos o observador e o observado.

O segundo eixo de pesquisa é desenvolvido no campo filosóficoepistemológico e é dedicado ao estudo da experiência através de métodos de primeira pessoa. Para o trabalho neste segundo eixo, Varela associou-se à filósofa Natalie Depraz e ao psicólogo Pierre Vermersch, ambos ligados à fenomenologia de Husserl. O recurso à fenomenologia deveu-se à sua contribuição ao estudo da experiência na filosofia ocidental. Vale lembrar que o domínio das ciências cognitivas na atualidade divide-se em duas vertentes: aquela cujos trabalhos apóiamse na fenomenologia e aquela cuja referência filosófica é buscada na filosofia analítica, como é o caso do cognitivismo computacional. É, portanto, com dois fenomenólogos que Varela veio a escrever seu último livro, publicado após sua morte precoce, com o título de On becoming aware (2003). A expressão becoming aware não possui uma tradução exata para o português, aproximando-se de "dar- 
se conta" ou de um ato de ciência, tal como comparece na expressão "tomar ciência" de alguma coisa. O termo awareness guarda um sentido dinâmico, referindo-se a algo que atinge a atenção de modo direto e súbito, possuindo além do sentido de registro, o de sua manutenção. Em francês, foi proposta a tradução de devenir-conscient (DEPRAZ; VARELA; VERMERSCH, 2000), que busca distingui-lo do mecanismo de tomada de consciência, tal como comparece na obra de J. Piaget (1978, p. 229), que mobiliza a reflexão e a compreensão pelo pensamento.

O tema do livro é o devir-consciente que, segundo os autores, tem lugar quando algo que nos habitava de modo implícito, difuso e virtual vem a aparecer no campo da experiência de modo explícito, claro e atual. O desafio é trazer ao cenário contemporâneo um tema até então inexplorado pela psicologia e pelas ciências cognitivas de modo geral. Fazendo do devir-consciente um problema, Varela, Depraz e Vermersch apostam na necessidade da investigação daquilo que na cognição é mais um processo que um estado mental, dando mais um passo para o esclarecimento de um processo sem sujeito, que as ciências cognitivas evidenciaram desde seu surgimento (DUPUY, 1996). Para a psicologia, é mais um problema que força a pensar e que exige a busca de novas soluções teóricas e metodológicas em seu domínio de atuação.

No livro On becoming aware a proposta de Depraz, Varela e Vermersch (2003) é estudar uma experiência singular, corporificada, precisa, individuada, sem que ela seja apreendida do ponto de vista de seu conteúdo. A investigação do devir-consciente é aquela de um ato, de uma atividade, de uma prática concreta. Trata-se do ato de tornar consciente, de modo explícito, claro, intuitivo, algo que nos habitava de modo pré-reflexivo, afetivo e opaco. O que se tem em vista é o conhecimento de uma experiência humana em ato, mutável e fluido. A questão é, então, como se pode vir, a saber, em primeira pessoa, como percebemos, nos lembramos, nos emocionamos.

Adotando uma posição nomeada de pragmática fenomenológica, os autores buscam o desenvolvimento de um novo método em primeira pessoa para sua investigação, lançando mão da auto-observação e de uma certa atenção a si, seguida de um relato descritivo da experiência. Como afirma Varela (2003b), a necessidade do desenvolvimento das metodologias de primeira pessoa já havia sido sublinhada por David Chalmers, que as considera essenciais para complementar o estudo da consciência através de métodos em terceira pessoa, utilizados pelas neurociências. Esta colocação evidencia que na obra de Varela qualquer tipo de reducionismo neurofisiológico encontra-se descartado. $\mathrm{O}$ reducionismo neurofisiológico consiste em reduzir o estudo científico da mente e mesmo da consciência a seus correlatos no sistema nervoso (CHANGEUX, 1985).

A proposta metodológica de Depraz, Varela e Vermersch é inspirada no método da redução fenomenológica apresentado por Husserl. Em sua obra, o método da redução consiste na colocação entre parênteses de todo juízo acerca do mundo. Os autores observam que embora esta colocação seja fundamental, Husserl não chegou a explicitar como ela se daria, nem tampouco atentou para as dificuldades que poderiam advir de sua implementação por parte de um agente concreto. 
A partir daí procuram lançar as condições para transformá-la em um verdadeiro método, definindo três gestos procedurais: a suspensão da atitude natural, a redireção da atenção do exterior para o interior e a mudança da qualidade da atenção, da busca para o acolhimento aberto da experiência (letting-go). Através desses três gestos, o objetivo é acessar um plano de virtualidade de si, no qual a experiência não é de um sujeito, mas pré-subjetiva.

No método da introspecção proposto por Wundt e Titchener, o treino dos sujeitos experimentais visava a transformação da auto-observação em primeira pessoa em observação em terceira pessoa, sobretudo através da análise da experiência, que conferia certo distanciamento e a separação entre o observador e o observado. No método da redução proposto por Varela, Depraz e Vermersch, o ato de voltar-se para si se faz através do ato refletinte (reflechissant), que consiste num gesto de conhecimento de si sem análise ou reflexão. Sua prática também exige, como na introspecção clássica, um treino específico e disciplinado. Mas o que se destaca é a necessidade do desenvolvimento de um aprendizado da atenção. A distinção em relação à introspecção não se dá pelo caráter supostamente espontâneo do ato de se voltar para si, que se oporia a uma habilidade treinada. Para os autores, há um inelutável aprendizado da atenção através de práticas concretas e que se faz através de exercícios reiterados em sessões sucessivas. A suspensão, a redireção e o letting-go são seguidos pela experiência da evidência intuitiva, que completa o ciclo básico do ato de devir-consciente, preenchendo o vazio característico da atenção aberta e dotando a experiência de clareza. A preocupação dos autores é ainda promover o treino da descrição de tal experiência, a fim de transformá-la em uma metodologia rigorosa de pesquisa.

O devir-consciente é um ato que ocorre em todos nós, mas a questão é como cultivá-lo através de práticas concretas. Trata-se de práticas de presença a si que envolvem uma suspensão da atitude natural e uma aprendizagem da atenção que possui dois movimentos: a redireção da atenção do mundo externo para o mundo interno e a mudança na qualidade da atenção, com o intuito de transformar uma atenção que busca em uma atenção aberta e não focalizada - a atenção do letting-go, do lâcher-prise, do deixar vir. Em outras palavras, visa transformar uma atenção que busca em uma atenção que encontra.

A questão do aprendizado e do cultivo do devir-consciente trouxe o problema da chamada segunda pessoa, que é alguém que ajuda a conduzir esse processo. Alguém que pergunta, evoca tais experiências e auxilia o acesso a algo que nos habita de modo implícito, opaco, afetivo, pré-refletido, conduzindo também no exercício da atenção peculiar que tais experiências requerem, seja através de práticas corporais, seja através de interrogações que sua investigação exige.

Os autores apresentam e examinam as peculiaridades de uma série de práticas de devir-consciente: o budismo, a psicoterapia, a entrevista de explicitação, a reza no cristianismo ortodoxo, a visão estereoscópica, o ensino de filosofia e o exercício da escrita. Levando-se em consideração que não se trata de uma lista fechada, o primeiro objetivo deste artigo é examinar a prática do devir-consciente em situações grupais. As idéias que apresentamos são basea- 
das em uma pesquisa de campo sobre rodas de poesia realizadas com mulheres de classes populares. A partir dela, gostaríamos de levantar duas questões, que incidem sobre a discussão metodológica de primeira, segunda e terceira pessoas - atualmente travada no campo dos novos estudos da experiência promovidos pelas ciências cognitivas. A primeira diz respeito ao estatuto da primeira pessoa quando nós falamos de um si mesmo que é um efeito emergente de uma rede de processos que se passam num plano pré-subjetivo, que é um plano de alteridade em relação ao si-mesmo constituído (DEPRAZ; VARELA, 2000). A segunda é como nós poderíamos falar de segunda pessoa no contexto de experiências com grupos, em situações coletivas. Nessas situações não há uma única pessoa com a qual se entra em relação, mas diversas pessoas que podem suscitar o acesso e o exercício das experiências de devir-consciente.

O segundo objetivo é analisar o caso específico de devir-consciente de experiências de breakdown (VARELA, 1994), que não são experiências recognitivas, mas de estranhamento de si e do mundo. Tais experiências, suscitadas pela leitura de poemas, revelam uma característica que excede a questão das metodologias de investigação da consciência. A partir deste caso, propomos que o devir-consciente é uma prática de produção de subjetividade.

Para desenvolver essa idéia, além de recorrer à fundamentação teórica de Depraz, Varela e Vermersch, lançamos mão das idéias de Gilbert Simondon para analisar o cruzamento dos planos aquém e além do indivíduo, que caracterizam a produção de subjetividade numa experiência de cognição coletiva. Para Simondon (1989) o indivíduo não é uma substância, matéria ou forma, mas excede o nível da unidade. Ele advém de um plano pré-individual de forças e potenciais. O problema é pensar sua ontogênese, o processo de individuação através do qual ele toma forma. Trata-se de uma inversão do modo tradicional de pensar: cumpre tomar o indivíduo através de seu processo de individuação e não a individuação através do indivíduo dado. Por sua vez, a forma individuada não esgota a realidade pré-individual, mas esta se mantém associada, caracterizando uma certa incompatibilidade em relação a si, fruto de uma tensão que se conserva. Nesse caso, para Simondon, o ser guarda em si uma heterogeneidade, possuindo uma capacidade de defasar-se em relação a si mesmo. No ser vivo a individuação é permanente. Além da relação com o meio, o ser vivo possui uma relação consigo, um regime de ressonâncias internas. A individuação psíquica é aquela de um ser problemático. A afetividade e a emotividade constituem a ressonância do ser em relação a si mesmo. Além disso, elas ligam o ser individuado à sua realidade pré-individual. Ao falar da individuação coletiva, Simondon ressalta que o indivíduo é associado ao grupo pela realidade pré-individual que traz consigo. Quando a dimensão pré-individual se reúne àquela de outros indivíduos, se individua uma unidade coletiva. As relações do grupo são ditas então transindividuais. Simondon afirma ainda que a base da realidade coletiva já está parcialmente contida em um indivíduo sob a forma da realidade pré-individual, que coexiste e permanece associada à realidade individuada. 
Depois de realizada a pesquisa de campo, e através de um exame dos relatos pretendemos destacar que: 1) a experiência literária se dá num plano pré-subjetivo, aquém da experiência de um indivíduo; 2) a experiência literária em situação grupal ultrapassa, num outro nível, a experiência individual, em função da leitura em voz alta e os comentários que se seguem à leitura do poema; 3) As experiências aquém e além do indivíduo se articulam e se potencializam, fazendo emergir uma dinâmica de ressonâncias que caracteriza a roda de poesia como uma figura da cognição coletiva.

\section{O DEVIR-CONSCIENTE EM RODAS DE POESIA}

Dando continuidade a experiências que utilizam a arte no contexto de trabalhos comunitários (KASTRUP, 2002; 2003), o projeto de rodas de poesia que realizamos com mulheres de classes populares foi montado em parceria com as professoras Angela Arruda, de psicologia, e Bebel Pantaleão, de literatura, e contou com cinco estagiários do curso de Psicologia da Universidade Federal do Rio de Janeiro. O projeto recebeu o título de "Jogando a poesia na roda" e a proposta foi fazer a leitura de poemas em voz alta e em grupo, no dispositivo roda de leitura. O objetivo do trabalho social foi promover uma prática de hospitalidade, no sentido definido por René Schérer (2000). As práticas de hospitalidade são práticas de encontro e acolhimento de diferença, de alteridade. No Brasil, mais do que voltado para o acolhimento de imigrantes, refugiados e estrangeiros que buscam entrada, moradia e acolhimento nas grandes cidades da Europa, o problema da hospitalidade está ligado às diferenças sociais, econômicas e culturais. O projeto "Jogando a poesia na roda" visou acolher, numa prática regular de leitura, um grupo heterogêneo composto de mulheres de classes populares, estudantes universitários, poetas e professores de psicologia e literatura.

A economia das práticas de hospitalidade não é a do interesse e da contrapartida, mas sim das trocas, dos agenciamentos, e também da oferta e do dom. No trabalho realizado, não se buscava admitir o outro em sua alteridade, em sua diferença, por tolerância ou concessão. Tratava-se antes de oferecer a hospitalidade, o que implica em reciprocidade. Oferecer o território da leitura, oferecer práticas de encontro e transversalização das diferenças é, ao mesmo tempo, oferecer-se a tais práticas. Trata-se aí de uma reciprocidade fundamental, que a ambigüidade da palavra hôte em francês expressa bem. Pois ela designa tanto o hospedeiro, o que recebe, quanto o hóspede, o que é recebido. O hospedeiro se inclina frente ao hóspede e se honra em recebê-lo. Oferecer a hospitalidade, receber o outro em sua alteridade, acolhê-lo, é também se oferecer às práticas de hospitalidade, experimentando uma distância em relação a si mesmo, uma distância íntima, para usar uma expressão de Francisco Varela (2001), que desloca a posição individualista que nos faz ver o mundo e os outros a partir de nós mesmos. Tais práticas exigem uma mudança de perspectiva, de atitude, uma espécie de conversão a um ponto de vista pluricêntrico, que nos faz ver através da alteridade (VARELA, 1994; KASTRUP, 2003). Trata-se, então, de mudar o olhar sobre si mesmo, a relação consigo. A hospitalidade envolve uma posição ética, pois a hos- 
pitalidade com o outro envolve a hospitalidade consigo mesmo, o acolhimento da própria alteridade que nos habita e constitui. Nossa experiência e também nossa aposta é que as práticas que promovem a experiência com a arte em trabalhos comunitários constituem instrumentos poderosos para a relação com a diferença que nos habita, abrindo para o acolhimento do outro em sua dimensão de alteridade.

Quando apresentamos a idéia de realizar rodas de leitura na "Fundação Gol de Letra", que atende crianças pobres da região de Itaipu, Niterói, alguns de seus funcionários argumentaram que nosso trabalho seria difícil de ser implementado, pois se dirigia a mulheres que não possuíam instrução, sendo a maioria delas empregadas domésticas de baixa escolaridade. Afirmamos então que isto não nos parecia um obstáculo, mas, ao contrário, ia ao encontro de nossa proposta de fazer da roda de poesia um dispositivo de produção de subjetividade e de transformação social, reunindo um grupo heterogêneo no que diz respeito a categorias sociais, econômicas e culturais. O que se visava era a abertura existencial de seus participantes e a ampliação de territórios habitados.

Além de um trabalho social, o projeto possuiu também o objetivo de investigar, através de uma pesquisa de campo, que tipo de comentário ou discussão seria desencadeada pela experiência poética, bem como a dinâmica que caracterizaria o encadeamento das falas que seriam "jogadas na roda". Objetivava ainda o desenvolvimento de um tipo de relato das experiências que teriam lugar na roda de poesia que não seguisse o modelo do relatório de pesquisa em terceira pessoa. Mas que também não tivesse o tom de um diário íntimo escrito do ponto de vista de um eu, e sim descrevesse o caráter coletivo da experiência.

Na dinâmica da roda, o responsável pela coordenação do trabalho alternava-se a cada encontro. Ele não possuía o papel de alguém que ia fornecer a interpretação "correta" da poesia lida, mas apenas animar a discussão, na qual esperava-se a participação de todos. A proposta era trabalhar com um grupo no qual a coordenação fosse distribuída, alternada e temporária. A idéia era fazer da roda uma figura da cognição coletiva, que entendemos em dois níveis distintos e complementares: o aquém e o além da experiência individual. A consideração desses dois níveis indica a retirada do indivíduo do papel de fonte e centro do processo de conhecimento.

A leitura de poemas apresentou-se como um meio de desencadear experiências de estranhamento de si, que não fossem recobertas pelos esquemas recognitivos dos participantes e, que nesse sentido, fossem pré-subjetivas. Segundo o poeta P. Leminski (1987, p. 285), “o poema não é como um conto, não é como um romance. Um conto, um romance, são transparentes, deixam o olhar passar até o sentido. Na poesia, não. O olhar não passa, o olhar pára nas palavras". Afirma adiante: "A atividade poética é uma coisa voltada para a palavra enquanto materialidade, a palavra enquanto uma coisa do mundo". E continua: "O poeta seria uma vítima da linguagem, a linguagem exerce uma violência sobre ele e ele sofre esta violência". Apostando que esta violência da palavra atinge o leitor, a proposta do projeto foi utilizar a poesia para suscitar experiências de estranhamento 
e surpresa, para colocar o leitor em contato com sua dimensão pré-egóica, présubjetiva e processual, aquém do indivíduo, promovendo um encontro com a alteridade que habita a subjetividade.

A prática da leitura de poemas em grupo heterogêneo foi a estratégia usada para o encontro com a alteridade num nível além do indivíduo, ou seja, num nível social. As rodas de poesia reuniam pessoas de diferentes idades, classes sociais, níveis de escolaridade e relação com a poesia. Em atividades dessa natureza, em geral, a diferença entre as pessoas é formatada através de relações hierarquizadas, baseadas em supostas diferenças de cultura, saber ou competência. No nosso caso, o objetivo era fazer com que essas diferenças pudessem ser diluídas nos momentos em que a experiência ultrapassa o plano subjetivo e pessoal e atinge o plano pré-subjetivo ou aquém do indivíduo. Na prática que propusemos, a heterogeneidade do grupo possibilitou, num nível além do indivíduo, ou seja, num nível social, a experiência com a alteridade do outro. Na roda de poesia, o encontro com a diferença em si mesmo é duplicada através do encontro com a diferença dos demais membros do grupo, com suas respectivas formas de viver, sentir e de ser afetado pela poesia. A leitura de poesias em roda é o elemento no qual esses dois planos "o aquém e o além do indivíduo se entrecruzam e se potencializam".

Antes de passar ao relato da experiência da roda, cabe ressaltar que o conceito de devir-consciente, tal como formulado por Depraz, Varela e Vermersch, possui uma acepção distinta da noção de devir na obra de Deleuze e Guattari (1980; KASTRUP, 2000). Os conceitos de devir-criança, devir-mulher, devir-animal e devir-imperceptível buscam dar conta de uma experiência que constitui uma saída do plano das formas constituídas, como é o caso da forma-homem, atingindo um plano de produção da subjetividade, caracterizado por uma dinâmica de fluxos heterogêneos. Para esses autores o devir consiste num movimento involutivo, que vai do plano das formas definidas (subjetivas e objetivas) ao plano pré-subjetivo e pré-objetivo de onde elas emergem. Para Depraz, Varela e Vermersch (2003), ao contrário, o devir-consciente é um movimento que transforma uma experiência pré-subjetiva, opaca e irrefletida numa experiência clara e intuitiva, portanto mais definida. Além disso, no contexto da filosofia de Deleuze e Guattari o devir atinge o plano do inconsciente maquínico, no qual as subjetividades são engendradas. Já para a fenomenologia, todas as experiências se dão no campo da consciência, embora este não seja considerado homogêneo, mas sim estratificado e dinâmico (DEPRAZ, 2001). O devir-consciente evidencia esta dinâmica da consciência, caracterizando um movimento de variação da experiência que vai da opacidade à clareza, da indistinção à distinção. Neste caso, podemos dizer que ele marca um movimento evolutivo de tomada de forma, e não um movimento involutivo. Com base em Deleuze e Guattari, não seria incorreto afirmar que o devir-consciente não se revelaria como um verdadeiro devir, mas apenas um movimento de gênese da experiência, um tornar-se ciente de algo. No entanto, nossa hipótese - que foi sustentada pelo trabalho com rodas de poesia e que nos fez seguir a tradução francesa e manter no presente texto a expressão devir-consciente - é que o gesto de suspensão provocado pelas experiências de breakdown produz uma bifurcação, uma mudança de extrato da consciência, acessando o plano de virtualidade de si, 
composto de experiências não conscientes, opacas e afetivas. Estas emergem em seguida, para cada um dos participantes, como experiências conscientes, ocasionando uma relação consigo caracterizada pelo sentimento de estranhamento e alteridade. Parece, portanto, justo, supor que o devir-consciente coloca em curso um processo de produção de subjetividade, que passa a ocorrer no momento em que há um devir da consciência em direção ao plano pré-subjetivo, marcado por uma certa atenção a si. Conforme veremos adiante, a explicitação de tais experiências na situação da roda potencializa esse processo de produção de subjetividade, marcando sua dimensão coletiva.

\section{UM BREVE RELATO DE UMA EXPERIÊNCIA COLETIVA}

Tomemos como exemplo um encontro para o qual foi levado para ser lido na roda o poema "Felicidade", de Vinicius de Moraes. Ao final da leitura, a pessoa que coordenava a roda naquele dia fez um comentário sobre o primeiro verso: "Tristeza não tem fim, felicidade sim". O verso, que falava de uma tristeza sem fim, havia provocado surpresa, tendo em vista o título do poema. Como diria Leminski, "o sentido não passou" e a fez parar na palavra felicidade. Após algum tempo de silêncio, afirmou que concordava com a idéia e acrescentou: "O que existe não é felicidade e sim momentos felizes". A observação foi seguida do comentário de um estagiário de que uma certa melancolia é a tônica dos poemas de Vinicius de Moraes, e dos poetas em geral. Afirmou que ele mesmo, como poeta, só escreve quando está triste, pois quando está contente faz outras coisas. Vai à praia, por exemplo. Uma das mulheres da comunidade acrescentou que para fazer poesia tem que haver uma certa "tribulação".

Sorrimos pelo caráter imprevisto deste depoimento, que revelava a firmeza e a prontidão de quem tinha conhecimento e intimidade com o fazer poético. A palavra tribulação, bem característica do vocabulário popular, significa uma sensação de aflição ou contrariedade, um estado mais próximo da perturbação do que da tristeza. A expressão usada pela mulher nos surpreendeu também por nomear de modo próprio o que chamamos, em linguagem filosófica, de experiência de problematização ou de estranhamento (KASTRUP, 1999). Movida pela leitura da poesia e pelos comentários que a ela se seguiram, a mulher lembrou de momentos em que viveu esta sensação de tribulação.

Há dias em que, ao acordar, sente-se tão esquisita que estranha até a cama, tão quentinha, aconchegante e familiar. "Dizem que é depressão. Mas eu digo para mim mesma: é esquisito, mas vai passar". Ela afirma que não aceita o rótulo de depressão e que convive com esse tipo de coisa. Pensei que, sendo ela uma mulher pobre e sacrificada pelo trabalho pesado, tudo que poderia querer era uma cama quente. Pensei na cama como figura do acolhimento, do sentimento do "em casa". Mas ela viu uma cama estranha. A cama suscitou outra experiência, distinta do reconhecimento, e a mulher me comove pela convivência e mesmo pelo acolhimento de sua experiência estranha, que nem ela entende, mas que lhe acomete e dá indícios da alteridade em si. Observo as mãos da mulher que fala. Mãos rudes, 
maltratadas, avermelhadas. Mãos de lavadeira. Será que ela é lavadeira? Ela tem as pontas dos dedos inchadas, as unhas rentes. A fala marcada pela sensibilidade poética e aquelas mãos. Percebi as mãos como ela percebia a cama, numa tensão entre duas coisas que pareciam incongruentes, mas que estavam presentes num mesmo bloco de experiência. Só depois pensei na propagação do estranhamento que houve ali, articulando o relato de uma alteridade interna, no seio de si, e da alteridade externa, no outro, se potencializando de modo recíproco.

Alguém chamou a atenção para um outro verso do poema: "A felicidade do pobre parece a grande ilusão do carnaval". A releitura do verso trouxe o tema da festa de carnaval para a roda. Surgiram opiniões, comentários de como no carnaval as diferenças sociais, tão marcantes no Brasil, de certa maneira desaparecem com o uso da fantasia. Fantasiados, ricos e pobres se reúnem num ritual de celebração do samba, música alegre e contagiante que faz os corpos dançarem em seu ritmo. O tom da conversa muda quando uma mulher comenta que certa vez assistiu na televisão imagens de pessoas pulando carnaval em câmara lenta, com uma música de fundo que não era samba. Como no caso da experiência com a cama, anteriormente relatada, imagens familiares emergiram de forma incomum e inesperada. A mulher contou que havia ficado perturbada pela estranheza daquela cena. Foi curioso notar que a experiência narrada guardava o mesmo tom do verso do poema, que falava da ilusão do carnaval. Ilusão de felicidade que surgiu desfeita quando o movimento dos corpos dançantes foi dissociado da música de carnaval.

Ainda na trilha das experiências de estranhamento, a mulher falou a respeito de um livro que havia lido sobre uma menina que calça um par de sapatos vermelhos, que a fazem dançar sem parar. Ao final do livro, não se sabe o que aconteceu com a menina de sapatos vermelhos. Ela está cansada de dançar, entra num quarto com o pai, fecha a porta e a história acaba com um grito. Sem saber o que ocorreu naquela cena, até hoje ela pensa naquele final intrigante, como se tal incógnita ainda a perturbasse. Ela diz que é como se até hoje escutasse aquele grito. "Foi um grito tão forte! Eu queria saber o que aconteceu". Mais uma vez a dança alegre é atravessada por algo de estranho. Agora é o grito alto e assustador que rasga a cena. Susto que força a pensar sobre a história que parece inacabada, aberta, sem fim.

No encadeamento das falas, foi evocada a cena final da novela Tieta. A novela é um gênero de programa de televisão muito popular no Brasil, sobretudo entre as mulheres. Tem emissão diária e conta uma história em capítulos. No caso em questão, a novela era baseada num romance de Jorge Amado, cuja história se passa numa pequena cidade do litoral do nordeste brasileiro. Girando em torno de uma mulher de nome Tieta, a novela tinha ingredientes de romance, com personagens marcantes e engraçados, não apresentando grande carga dramática. Entretanto, na fala da mulher o que aparece não é a história de Tieta, e sim a cena final da novela, que mostra a cidade sendo coberta e desaparecendo sob uma tempestade de areia. A mulher relata que ficou "invocada" com aquela cena. Jamais a esqueceu, ela se mantém até hoje viva dentro dela. Seria esperado que o tema, "novela", puxasse um conjunto de 
comentários rememorativos acerca da história, que é bem conhecida. No entanto, como no tema do carnaval, fomos surpreendidos pelo relato de experiências incomuns e inesperadas.

Aos poucos fomos constatando que a leitura da poesia, ao produzir experiências de surpresa e estranhamento, tem o poder de suscitar outras experiências dessa natureza, que extrapolam o que efetivamente é trazido pelo poema lido. Algumas falas referem-se diretamente à presença da poesia na vida em seus momentos de "tribulação", como havia pontuado uma das mulheres. É ainda ela quem relata que certa vez foi acometida por grande aflição e tristeza no dia em que ia deixar a casa de sua irmã, com quem havia morado durante longo tempo. Sem ter coragem de se despedir dela e tomada pela tristeza gerada pelo momento de partir, decidiu deixar um bilhete. Nesse momento, veio-lhe uma idéia. Lembrou-se que goiaba era a fruta predileta da irmã. Decidiu então deixar para ela, juntamente com o bilhete de despedida, uma goiaba, como forma de expressar o seu carinho. Ela afirma que não sabe como se lembrou da goiaba, que a lembrança veio não sabe de onde. Era como a poesia brotando nos momentos de tribulação.

Ao final do encontro em que, inspirados pela poesia lida, falamos mais de tribulação, estranhamento e tristeza do que da felicidade no sentido mais banal, não saímos entristecidos ou ensimesmados. Experimentamos a alteridade, aprendendo a acolhê-la em nós e nos outros.

Procurando fazer um balanço do que foi relatado acima, verificamos que o que foi jogado na roda foram experiências nas quais se observa uma dobra entre os planos cognitivo e afetivo (DEPRAZ; VARELA, 2000). As que prevalecem não são aquelas que foram experimentadas do ponto de vista de um "si mesmo" constituído ou de eu reflexivo. São experiências que acometem o eu, que ele não controla e não sabe de onde vêm. São ao mesmo tempo íntimas e estrangeiras. No entanto, elas chegam com a clareza da intuição e vêm acompanhadas de um sentimento de certeza de terem sido experimentadas. Não são apenas experiências relativas à leitura do poema, mas que são evocadas por ela, em função de um tipo de ressonância afetiva. As lembranças são evocadas em função de um tom de estranhamento que lhes é comum.

As falas encadeiam-se de modo peculiar. A experiência com a poesia não suscitou falas nas quais se buscasse sentido ou interpretação de versos até certo ponto enigmáticos sobre o tema da felicidade. A experiência poética propagou-se no relato de outras experiências da mesma natureza. As falas articulam-se durante o encontro como um agenciamento coletivo de enunciação (DELEUZE; GUATTARI, 1980). Este conceito baseia-se no conceito de Baktine de discurso indireto livre, que contém ao mesmo tempo dois modos de narrativa: o discurso direto e o discurso indireto. $\mathrm{O}$ discurso direto caracteriza a enunciação de alguém, mantendo-se sua forma original, entre aspas. É uma narrativa em primeira pessoa, na forma pronominal "eu". O discurso indireto é um discurso em terceira pessoa, contendo comentários, impressões e elementos de ligação. Um narrador relata, a seu modo, a fala de outra pessoa. $\mathrm{O}$ discurso indireto livre é um discurso na forma pronominal terceira pessoa, mas que mantém conteúdos, expressões do discurso 
narrado e a própria enunciação dos personagens. Ele revela a heterogeneidade interna ao discurso (TEDESCO, 1999). Baktine enfatiza a interferência entre os discursos, que perdem independência. A articulação não se baseia num código comum nem se faz por adição. Embora inclua a experiência do próprio narrador, não se trata de um ponto de vista pessoal, nem de um ponto de vista que oscila entre o individual e o social. Revela a linguagem em sua dimensão coletiva e polifônica. Deleuze e Guattari (1980) sublinham que toda linguagem é um discurso indireto livre, enfatizando seu caráter de variação e de devir. Um enunciado remete a outros, compondo um bloco de discursos articulados, um conjunto de dizeres que caracterizam o caráter eminentemente plural e coletivo da enunciação.

Entendo o relato como um agenciamento coletivo de enunciação, que procura colocar em evidência o fato de que as falas se aproximam por divergências e se atravessam num plano pré-individual. Sua articulação não se faz sobre o plano de um código comum. Os agenciamentos se produzem precisamente a partir das irregularidades da linguagem e dos pontos de resistência ao código comum, que se revelam na poesia e nos comentários que se seguem à leitura.

A conversa faz surgir um plano coletivo, no qual se reúnem as falas do poeta, dos participantes do grupo, de outros autores que são evocados, personagens e pessoas conhecidas, que ampliam ainda mais a heterogeneidade da roda. Outros agentes são integrados no momento de fazer a descrição, no relato da experiência. Sob a perspectiva da experiência coletiva, o relato não se fecha, podendo ser acrescido de mais e mais falas, num movimento cujos limites seriam difíceis de precisar. $\mathrm{O}$ relato visou evidenciar uma dinâmica coletiva de ressonâncias. A coordenação distribuída facilita a condução do trabalho, pois o comparecimento das falas não parte de perguntas formuladas por um coordenador central. Uma fala puxa a outra e neste movimento o centro da roda vai-se deslocando. A primeira pessoa é aquela que experimenta o ato de devir-consciente e descreve sua experiência. Sua descrição em voz alta faz com que ela funcione como uma segunda pessoa, atuando a fim de propagar o devir-consciente em alguém que, neste momento, assume o papel de primeira pessoa. A descrição da experiência suscitada atua, por sua vez, como segunda pessoa para outro participante da roda e assim sucessivamente.

Creio que a experiência poética, que problematiza o sentido habitual das palavras, que deixa perguntas mais do que fornece respostas, é um instrumento poderoso no sentido de proporcionar o acesso à virtualidade do si. Vivida na situação coletiva da roda de poesia, a função segunda pessoa, isto é, a função de acompanhar o ato de devir consciente, de propor práticas, de interrogar para suscitálo, se multiplica numa rede de relações múltiplas, paralelas e descentralizadas.

\section{O AQUÉM E O ALÉM DA EXPERIÊNCIA INDIVIDUAL E ALGUMAS INTERROGAÇÕES METODOLÓGICAS}

Frente ao cenário das discussões metodológicas atualmente travadas nas ciências cognitivas, e tendo em vista a pesquisa realizada, gostaríamos de voltar às duas questões levantadas no início. A primeira, diz respeito ao estatuto da 
primeira pessoa e a segunda é como nós poderíamos falar da segunda pessoa no contexto de experiências com grupos, em situações coletivas.

Segundo Depraz, Varela e Vermersch (2003), que seguem Husserl nesta formulação, a experiência estética tem uma natureza especial, sendo capaz de suspender a atitude natural, os julgamentos acerca do mundo externo. A experiência estética surge também como uma experiência que desloca o eu do centro e da pilotagem do processo de conhecimento. É isso que se observa na experiência poética, que produz breakdowns, ou seja, quebras, descontinuidades e rachaduras no fluxo recognitivo habitual.

A leitura é uma experiência que nos conduz a um afastamento do mundo externo, suscitando uma atitude de recolhimento e de relação consigo. No entanto, ela promove uma relação consigo aquém do si mesmo constituído. Com efeito, o leitor entra em relação consigo e ao mesmo tempo sai da posição do "eu penso" ou do "eu sei". A experiência literária ocorre no momento em que o leitor levanta os olhos da página e deixa que o texto afete a subjetividade. O texto, em sua dimensão de alteridade, afeta e acorda a alteridade que habita o leitor. Ele desencadeia, então, o que podemos chamar de momento de alterização do eu. A surpresa estética promove a suspensão do juízo e do fluxo recognitivo habitual. A descontinuidade experimentada faz com que o leitor redirecione a atenção para si. Tal redireção se faz sob o efeito da surpresa, ou seja, quando a atividade de recognição se encontra suspensa e o eu deslocado do centro do processo cognitivo. Em relação ao problema dos métodos de primeira pessoa, cabe então sublinhar que, neste contexto, ela não se identifica com um eu. Após a leitura do poema, sente-se uma desaceleração do tempo e um certo vazio difícil de sustentar. Nesse momento, em situação de roda, muitas vezes surge um comentário de outra pessoa, que procura traduzir em palavras uma experiência que para outros é ainda indizível. Mesmo que o laço com a experiência de referência seja algo vago, mera expressão de uma sensação ainda sob o impacto da leitura recente - ruídos indefinidos, interjeições, expressões faciais, sorrisos, signos de cumplicidade - a fala suscita outras falas, concorrendo para a emergência de outras experiências de devir-consciente. Essa fala coletiva, composta aos poucos por pedaços de palavras e frases, algumas sem possuírem sentido definido, vai reunindo o grupo de modo peculiar. Surge uma dinâmica de ressonância. Subjetividades que vibram num mesmo tom entram em sintonia, mas esta dinâmica pode se desfazer temporariamente, quando uma outra pessoa assume a palavra, deslocando a discussão para outro verso do poema ou trazendo à cena uma outra lembrança. Creio, então, que se pode concluir que a "segunda pessoa" deve ser entendida como uma função, e não como uma pessoa, podendo ser exercida pelo próprio grupo.

A experiência literária vivida em situação grupal é uma experiência de encontro com o texto, com as pessoas e consigo mesmo, concorrendo tanto para o acolhimento da alteridade em si quanto para o acolhimento do outro em sua alteridade. Para concluir, gostaria de colocar que em situação de roda de poesia, o devir-consciente revela características que o afastam de uma experiência individual stricto sensu. Evidentemente ele é praticado por cada um dos integrantes da 
roda. Cada um experimenta sua própria atividade cognitiva. Também é cada um que descreve e comenta a sua experiência. No entanto, tomando como base que o devir-consciente emerge de um plano afetivo pré-egóico, plano que não é controlado por um eu, que inclusive não se reconhece como o piloto desse ato, deve-se ver aí uma dimensão coletiva, aqui tomada no sentido de pré-individual. Do ponto de vista do método, parece justo concluir que a noção de primeira pessoa encontra-se aqui ampliada. A primeira pessoa não se identifica com um eu, com um si mesmo constituído, embora a experiência seja sempre singular, concreta, precisa e situada. No caso do trabalho com grupos heterogêneos, o devir-consciente acentua sua dimensão coletiva. Praticado num plano social, a chamada segunda pessoa é distribuída e é o grupo, em sua pluralidade, que auxilia no acesso ao devir-consciente.

A roda de poesia parece revelar essa dimensão coletiva. Dimensão esta que faz da prática e da aprendizagem do devir-consciente não apenas um novo tema a ser investigado. Além de ser um tema de pesquisa (pois ele é isso também, e dos mais instigantes), sua prática não serve apenas para treinar sujeitos para a investigação da consciência em sua dimensão de ato, em sua fluidez e movimento. A prática do devir-consciente revela-se como uma prática de si, uma prática de transformação de si e de produção de subjetividade. É certo que tudo isso está indicado e bem explicado no livro de Natalie Depraz, Francisco Varela e Pierre Vermersch. Os exemplos que eles dão: o budismo, a entrevista de explicitação, a reza, a clínica, a sessão de escrita, o aprendizado da filosofia e a visão estereoscópica, dão testemunho de seu reconhecimento de sua dimensão de prática de aprendizagem e de produção de subjetividade. Mas procuramos trazer aqui o problema da cognição coletiva, das práticas de devir-consciente em grupos heterogêneos. Foi nesse sentido que trouxemos a questão da roda de leitura, esta figura da cognição coletiva, que é ao mesmo tempo pesquisa e intervenção.

\section{REFERÊNCIAS}

CHANGEUX, J. P. O homem neuronal. Lisboa: Publicações Don Quixote, 1985. COMTE, A. Curso de Filosofia Positiva. In: Os Pensadores. São Paulo: Abril, 1842/1972.

DEPRAZ, N. La conscience: approches croisées, des classiques aux sciences cognitives. Paris: Armand Colin, 2001.

DEPRAZ, N; VARELA, F; VERMERSCH, P. La réduction à l'épreuve de l'expérience. Études phénoménologiques, Paris, n. 31-32, p. 165-184, nov. 2000.

. On becoming aware: advances in consciousness research. Amsterdam: John Benjamins Publishing, 2003.

DEPRAZ, N.; VARELA, F. At the source of time: valence and constitutional dynamics of affect. 2000. Disponível em: <www.liane.net/areobase>. Acesso em: set. 2002.

DELEUZE, G.; GUATTARI, F. Mille Plateaux. Paris: Minuit, 1980.

DUPUY, J.P. Nas origens das ciências cognitivas. São Paulo: UNESP, 1996. 
KASTRUP, V. A invenção de si e do mundo. Campinas-São Paulo: Papirus, 1999. . O devir-criança e a cognição contemporânea. Psicologia: Reflexão e Crítica, [S.1.], v.13, n. 3, p. 373-382, 2000.

A propos de l'apprentissage de la compétence éthique. Intellectica, [S.1.], v. 35, n. 3, p. 299-322, sept./déc, 2002.

Production de subjectivités en atelier de lecture. Chimères, v. 49, n. 3, p. 95-110, set/déc , 2003.

LEMINSKI, P. "Poesia: a paixão da linguagem”. In: . Os sentidos da paixão. São Paulo: Companhia das Letras, 1987.

MATURANA, H.; VARELA, F. A árvore do conhecimento. Campinas: Editorial Psy, 1995.

PIAGET, J. Problemas de psicologia genética. São Paulo: Abril Cultural, 1978. (Os pensadores: Piaget)

SCHÉRER, R. Un parcours critique. Paris: Kimé, 2000.

SEARLE, J. O mistério da consciência. São Paulo: Paz e Terra, 1998.

SIMONDON, G. L'individuation psychique et collective. Paris: Aubier - Res, 1989.

TEDESCO, S. Estilo e subjetividade - considerações a partir do estudo da linguagem. 1999. Tese (Doutorado)-PUC-SP, São Paulo, 1999.

VARELA, F. Conhecer. Lisboa: Instituto Piaget, 1994. . Sobre a competência ética. Lisboa: Ed. 70, 1994.

. Intimate distances. Journal of Consciousness Studies, [S.1.], v. 8, n. 57, p. 259-271, May/July 2001.

. O reencantamento do concreto. Cadernos de Subjetividade/Núcleo de Estudos e Pesquisas da Subjetividade do Programa de Estudos PósGraduados em Psicologia Clínica da PUC-SP - O reencantamento do concreto. São Paulo: Hucitec/EDUC, 2003.

O estudo científico da consciência. In: Goleman, D. (Org). Como lidar com emoções destrutivas. Rio de Janeiro: Campus, 2003.

VARELA, F.; THOMPSON, E.; ROSCH, E. A mente incorporada. Porto Alegre: Artmed, 2003.

VARELA, F. et al. The brainweb: phase synchronization and large-scale integration. Nature Reviews - Neuroscience v. 2, n. 22 , p.229-239, apr. 2001.

Recebido em: julho/2004.

Aceito em: setembro/2005. 